\title{
Compliance Factors of Malaysian Private Entity Reporting Standard (MPERS) by Small Medium Enterprises (SMEs)
}

\author{
Nurul Nazlia Jamil ${ }^{1}$, Nathasa Mazna Ramli ${ }^{1}$, Ainulashikin Marzuki ${ }^{1} \&$ Nurul Nadiah Ahmad ${ }^{2}$ \\ ${ }^{1}$ Faculty of Economics and Muamalat, Universiti Sains Islam Malaysia (USIM), Malaysia \\ ${ }^{2}$ College of Business and Accounting, Universiti Tenaga Nasional (UNITEN), Malaysia \\ Correspondence: Nurul Nazlia Jamil, Faculty of Economics and Muamalat, Universiti Sains Islam Malaysia (USIM), \\ Malaysia. Tel: 60-6-797-8670. E-mail: nurulnazlia@usim.edu.my
}

Received: September 27, 2020

Accepted: December 8, 2020

Online Published: January 20, 2021

doi:10.5430/ijfr.v12n3p149

URL: https://doi.org/10.5430/ijfr.v12n3p149

\begin{abstract}
The study objectively reports the findings on a questionnaire survey when examining the factors affecting Malaysian Private Entity Reporting Standard (MPERS) compliance in Malaysia by small and medium enterprises (SMEs). The study is based on a professional accountant questionnaire survey involving a sample of 176 respondents who are currently involved in the implementation of MPERS. The result reveals that the main factors affecting the SMEs' compliance with MPERS were the legal limitations and requirements. The study also finds that the perception, size of entities, management and accounting skills of the external user, and consideration of costs and benefits, have little impact on MPERS compliance. Furthermore, the study contributes to the literature of the financial reporting standard for SMEs by providing empirical from Malaysia's local context that uses MPERS and how the theses affect reporting practices. To adopt the 'true and fair view' financial reporting standard when explaining the firm's financial performance and financial position, this study should be the interest of regulatory authority, standard setters, and owners of SMEs themselves.
\end{abstract}

Keywords: compliance, financial reporting standard, small medium enterprises, Malaysia

\section{Introduction}

Small and medium enterprises (SMEs) in Malaysia adopting the Malaysian Private Entity Reporting Standard (MPERS) from 1st January 2016. This is a new version of the Financial Statements Reporting Guideline as previously outdated as the Private Entity Reporting Standard (PERS) provides a new alternative standard to make SMEs in Malaysia more attractive to foreign investors. Therefore, given the significant role of small and medium-sized enterprises (SMEs) in economic development, a private entity would benefit from a quantum leap in matching its financial reporting with current global financial reporting, in addition to other advantages such as standardized treatment and presentation, accounting policy choices and less rule-based specifications (Salin, 2017).

To date, little academic research regarding the implementation of MPERS and the challenges it poses to reporting entities has been published. Jamil et al. (2020) found that the market, especially small and medium-sized enterprise owners, does not have enough time to make for adoption until it becomes mandatory. It creates therefore difficulties in avoiding the penalties for any incompliance. Aziz et al. (2019), on the other hand, explored the readiness of accounting practitioners to implement MPERS. The result suggests the accounting practitioners are in favor of MPERS implementation. This is also supported by the result that the accountants or auditors have recognized the need to adopt MPERS, while the long-term benefits or results of compliance with MPERS remain unclear (Aziz et al., 2019).

This study aims to examine factors influencing compliance of SMEs with MPERS in the setting in Malaysia. The study is a survey questionnaire of accounting practitioners working with small and medium-sized companies. An analysis of the empirical evidence finds that the legal restrictions were the key factor affecting SME compliance with MPERS. The study also reveals that the perception, size of entities, management and accounting skills of the external user, and consideration of costs and benefits, have little impact on MPERS compliance.

The paper is laid out as follows. Section 2 discusses a literature review of related studies. Section 3 sets out the context of the Malaysian study and the development of MPERS. Then the following section describes the research 
methodology used in this study. Section 4 presents the results and the discussion and finally, Section 5 concludes the paper with some conclusions and recommendations for future research.

\section{Literature Review}

Historically, during July 2009 the International Accounting Standards Board (IASB) published the International Financial Reporting Standard (IFRS) for SMEs. Ideally, the published standard is to ensure that SMEs have a globally comparable universal standard, and that reporting quality can be recognized internationally (Weaver and Woods, 2005). Furthermore, there are still many debates in the literature that discuss financial reporting purposely to cater to the financial information needed by external users (Holmes et al., 1991, Eierle, 2005, and Williams \& Tower, 1998). According to the study conducted by Knutson and Wichmann (1984), the underpinnings of the debate highlighted that shareholders and also the financial institution demand the same degree of protection when encounter with small and medium enterprises as they experience with larger enterprises, particularly those that fall within the publicly listed companies.

Therefore, given the importance of IFRS for SMEs, the IASB claims that implementation IFRS for SMEs improves access to international financing by harmonizing financial reporting (IASB, 2009a). This is significant as more than 95\% of business worldwide represent SMEs and account for more than $65 \%$ of employment (IASB, 2017).This reflects that SMEs are making a huge contribution to many countries in terms of job creation, technological advancement, and economic output (Pais and Bonito, 2018). In the Asia Pacific, for example, SMEs have become the largest employer contributing to the countries ' economic output (APEC, 2016). Similarly, SMEs account for about 99.8 percent of non-financial companies in the European context and develop 57.4 percent of value-added (European Commission, 2016).

However, due to the complexity of current reporting requirements and the high cost of compliance, the current IFRS reporting framework creates challenges for SMEs (Koppeschaar, 2012; Albu et al., 2014; Kaya and Koch, 2015). Small businesses generally consist of only a few staff members with very limited financial expertise and ultimately lead to limited resources. They must therefore incur additional costs to comply with the IFRS requirements which demand technical skills and extensive disclosure for the purposes of reporting.

Overall, previous studies also reveal that the implementation of IFRS for SMEs has brought different arguments, particularly against differential reporting, cost-benefit factor, and standard-related issues of recognition and measurement (Perera and Chand, 2015). For IASB, the main objective of introducing the IFRS for SMEs is to improve the usefulness of the decision and to reduce the information asymmetry for SMEs across the region. Similarly, few other factors that influence the adoption of IFRS for SMEs, such as the study conducted by Pais and Bonito (2018), IFRS for SMEs are more likely to be implemented by countries with a common law system. This is because the fact that adoption can reduce the cost of developing its own financial accounting standard. The relationship could also be influenced by other factors such as foreign aid, education level, and quality of the national financial accounting standards.

Despite numerous studies conducted on IFRS adoption problems for small businesses, the compliance factors also need to be considered as important tools for adopting the standard. The increasing complexity of the global business phenomena has likely led to more stringent reporting requirements and costs (Perera and Chand, 2015; Pais and Bonito, 2018 and Thi et al., 2020). Compliance with the accounting standard has become prominent for SMEs to adhere to as the international regulatory matter has been recognized. This can differentiate the reporting segment particularly with the reporting and auditing requirement between small and large entities (Kaya and Koch, 2015).

In recognition of the benefits of the reporting standard for SMEs, Malaysia has adopted the IFRS for SMEs, namely MPERS, which corresponds to local needs that can provide users with more relevant and useful information (MASB 2016). The current study is motivated by Salin (2017) findings highlighting the benefits and challenges of implementing MPERS, which among them, the owners of small and medium-sized enterprises do not have enough time to make the necessary preparations before adoption is compulsory. It is hoped that this study will also be able to identify MPERS's compliance factor to ensure SMEs do not have uncertainty about adhering to this new regulatory setting.

In addition, as mentioned by Jamil et al. (2020), MPERS can be a benchmark of financial reporting across ASEAN religions in the SMEs finance reporting debate that is currently taking place in several countries due to a similar market setting and climate. It can also be used as kick-start for cooperation with MPERS, to go globally and across ASEAN. Furthermore, one of the significant key impact or changes of MPERS is concept of undue cost or effort exemption. According to Tong (2014), numerous measurement exemptions were given in the original MPERS based 
on under-cost or effort. But there was no explanation for the concept of "undue cost or effort." The amended MPERS in 2015 clarifies that it depends on the specific circumstances of the entity and on the management's judgement of the costs and benefits of applying that requirement to consider whether obtaining or determining the information necessary to fulfil a requirement would involve undue costs or effort. Similarly, Aziz et al. (2018) mentioned that this judgement requires consideration of how not that information having could affect the economic decisions of those who are expected to use the financial statements. The exemption is included in a study by Jamil et al. (2020) report to assist first time adoption companies and is not deliberately defined under MPERS. The exemption provides that an entity does not need to comply with certain MPERS requirements if compliance results in undue management costs or effort. This is specific to the circumstances of the entity and will involve the judgement of the management in evaluating the costs and benefits. The concept of 'undue cost or effort' was also introduced by MPERS, whereby an asset or liability is exempt from applying the fair value method should there be undue costs or effort during the valuation process (MIA, 2018).

As a result, all private entities are required to apply MPERS starting 1st January 2016, therefore management needs to define the gap and examine the implications to ensure a smooth transition into the new framework. It will lead to convergence and comparability of local business with foreign business by having Malaysian own version of the standard called MPERS. Hence, the comparability and consistency of the financial statements of local SMEs firms is seen to be improved. In addition, one significant motivation is that MPERS adoption studies are still very infant in Malaysia. Therefore, the compliance factor issuing individual financial reporting is important to study. Subsequently, it is also an important contribution to the study to highlight the factors that could impact the country-level compliance of MPERS as the MPERS is unique to SMEs, hence the contribution of the institutional characteristics of countries could become an important issue to study.

\subsection{The Context of the Study: Malaysia}

In Malaysia, with few amendments, adopting MPERS according to the global IFRS standard for SMEs. For example, there are few changes related to the Private Entities Section One, Consolidated and Separate Financial Statements Section Nine, and Specialized Activities Section Thirty-Four. Ideally, the changes were made to meet the global requirement and increase the visibility of the performance of SMEs in Malaysia to be comparable with others. Furthermore, the purpose of enhanced SME reporting is reducing the complexity of the standards and therefore reporting can be informative for users and other stakeholders (Salin, 2017; Jamil et al. 2020).

Migration to the new MPERS has become mandatory by $1^{\text {st }}$ January 2016 and those involving the private entities. In Malaysia, the definition of private entities is a private company that enforces the Securities Commission and Central Bank of Malaysia, incorporated under the 1965 Companies Act, and not under the jurisdiction of the law. Similarly, this particular entity is not a subsidiary or associate or jointly controlled by the entity requiring the Securities Commission and the Central Bank of Malaysia to submit financial statements (MASB, 2014).

Compliance issues may become significant compared with PERS to be explored. MPERS implementation restricts accounting policy and thus may create dilemmas in the process of complying with the standard for some companies. Aziz et al. (2018) highlighted in the dilemma would affect those involved with companies involved in Construction and Property Development as, from a technical perspective, the method of borrowing costs should be treated as expenses rather than capitalization. Besides, companies with intangible assets need to recognize their asset's finite life and amortize the assets over 10 years. Similarly, in the case of plantation entities, they are required to measure their biological assets at fair value, creating additional costs in valuing those assets for them (Sia et al., 2018).

At this point, although the accounting professional bodies also discussed MPERS in many seminars or workshops, yet very little detail on the compliance factor has been explored. Only a few studies conducted on MPERS readiness, cost, and benefits yet very limited empirical evidence on the compliance factor (Aziz et al., 2018, and Salin, 2017).

\section{Research Methodology}

\subsection{Data Collection and Analyses}

The current study uses a quantitative method to examine compliance factors on the Malaysian SMEs' implementation of MPERS. According to Dillman (2000), the survey method is adequate to test characteristic and sociological variables on the empirical evidence. The study developed the hypotheses and used the variables that should be included in the survey. Furthermore, the survey had been distributed to nearly 200 accounting practitioners directly involved in the implementation of MPERS. Of the 200 respondents, however, only 176 respond fully to the surveys. According to the study conducted by Barker and Noonan (1996), it was stated that the best indication for understanding the standards compliance issues is through those directly involved with the standard. The survey was 
therefore suitable and fits the accounting practitioners who work with SMEs and directly involve the implementation of MPERS.

The collection of data contained handing out the questionnaire around July to October 2019 to the respondents. Analysis of quantitative data was carried out based on data collected from the questionnaire. In order to examine the factors of compliance with the implementation of MPERS, a coding process was also conducted. Two sections consisted of the investigative instrument. In the first section, subjects were required to provide demographic information such as gender, level of formal education, experience level, and firm details. The second section consisted of five compliance factor variables for small and medium-sized enterprises, each of which dealt with different aspects of MPERS in Malaysia. The respondents will be asked to state their degree of agreement or disagreement with each of those statements on a five-point Likert scale. The statements were developed by academic and professional literature, based on criticism and comments on MPERS for SMEs.

\subsection{Hypothesis Development}

The study attempts to provide answers to one major research question: what factors influence compliance with MPERS SMEs in Malaysia? There are about five factors based on the literature review that might influence compliance with accounting standards, including legal limitation and requirement, the perception of the external user, the stakeholder's demand to improve the information quality of SME reporting, the size of business entities, the consideration of costs and benefits and management and accounting abilities. Following Creswell (2003), the study constructs null-alternative hypotheses of the factors mentioned earlier:

H1. HO: There is no relation between legal restrictions and requirements for SMEs to comply with the implementation of MPERS.

This hypothesis relating to the idea of legal limitation and requirement can create complexity for SMEs to comply with the MPERS. In Malaysia, the use of IFRS for SMEs has been widely applied but MPERS ideally fits local business demand and updates the standard following the changes in this current business environment. MPERS's infancy, however, leads to the question of how compliance with the legal requirement might affect SMEs.

H2.HO: There is no relation between the perceptions of the external user that SMEs comply with the implementation of MPERS.

The financial accounting information that reported from internal and external parties in the financial statements mainly to serve the needs of the users. This hypothesis assumes that external users such as accounting practitioners such as tax agents or the perception of auditors do not affect SMEs' compliance with the implementation of MPERS.

H3.HO: There is no relationship between the size of the entities and SMEs that comply with the implementation of MPERS.

The MPERS is designed to increase the global comparability of the financial statements and this hypothesis, therefore, assumes that MPERS that fits the local standard or setting following the IFRS can be compared without taking into account the size.

H4.HO: There is no relation between the SMEs' consideration of costs and benefits with the implementation of MPERS.

This hypothesis assumes that among the preparers there is still a lack of awareness of cost and benefit consideration and therefore the costs and benefits were not well researched as regards standard implementation. Therefore, the consideration of costs and benefits may not be an important compliance factor for the business.

H5.HO: There is no relationship between the management and accounting skills on SME compliance with the implementation of MPERS.

The evidence from prior literature has resulted in a lack of management and accounting expertise having a negative effect on the preparation of financial statement. Therefore, if it does not follow the proper standard as highlighted by the regulator it could directly affect the statement. This hypothesis was therefore constructed to analyses the findings regarding the implementation of MPERS.

\section{Results}

\subsection{Compliance Factors of MPERS Implementation by SMEs in Malaysia}

Following the suggested literature, the current study adopted a list of five factors that may affect the implementation of MPERS. The respondents were asked how they viewed the significance of the five factors that could affect their reporting practises including: 
1) Legal restriction and requirements (LEGAL)

2) External user's perceptions (EXUSER)

3) Size of entities (SIZE)

4) Cost and benefits consideration (COSTBENEFIT)

5) Management and Accounting Skills (SKILLS)

These are all the factors stated in the survey questionnaire that the respondents were to answer. The results are presented in Table 1. Table 1 shows that size of entities among small and medium-sized enterprises was not the main factor of compliance with MPERS. This is consistent with Nijam's study (2016), which stated that the size of entities was the most significant factor related to volunteer adoption. Since MPERS has become compulsory, other factors are therefore more relevant to the standard in terms of its compliance.

In various notes, the respondents perceived legal restriction and requirements as the principal motivation or factor for MPERS compliance. Compared to other factors, the highest mean of 3.955 indicates that the accounting regulations perceived by the respondents influence the acceptance and compliance of the national accounting standards. The division of legal systems into common law and code law is understandable, and this is the factor that affects the standard of accounting (Doupnik and Slater, 1995). The system of common law is created on the basis of the local context in which it can fit the national users' demands. Consequently, the result is consistent with the outcomes of Felski (2015), Kolsi and Zehri (2013, and Pais and Bonito (2018), in which it was stressed that the common law system could influence the adoption of the reporting standard.

On the other hand, management and accounting skills tend to have less effect on the factor of SMEs in Malaysia complying with MPERS. Similarly, the consideration of costs and benefits also does not become a stronger factor affecting standards compliance. In the case of SMEs in Malaysia, for example, the SME Corp is one of the institutions that provide guidance, training, business consultancy, and financial support to SMEs in Malaysia. This external guidance could therefore reduce their complexity in complying with the standard and in keeping with the result indicating that the skills have less effect on compliance.

Table 1. Compliance factors of MPERS implementation by SMEs

\begin{tabular}{lllll}
\hline Factors & Min & Max & Mean & SD \\
\hline Legal restriction and requirements & 1 & 5 & 3.955 & 0.5638 \\
External user's perceptions & 1 & 5 & 3.841 & 0.7362 \\
Management and Accounting Skills & 1 & 5 & 3.835 & 0.7936 \\
Cost and Benefits of Consideration & 1 & 5 & 3.716 & 0.6837 \\
Size of entities & 1 & 5 & 3.571 & 0.7763 \\
\hline
\end{tabular}

Accordingly, the Chi-square tests included independent variables to investigate the relationship between the variables and the dependent variables in terms of their compliance with the MPERS (COMPLY) in responding to the study objective which is to investigate factors affecting MPERS compliance by SMEs in Malaysia's setting. The findings below are set out in Table 2 .

The result below shows some significant association on the factors that affect SMEs in Malaysia complying with MPERS. These findings can be used to dismiss or support the hypotheses that this study has developed. The results of the hypothesis presented in Table 3 which show whether the null hypotheses was accepted or rejected. The results in Table 2 highlighted that legal restrictions and requirements are significantly linked to SMEs complying with the MPERS standard, as the p-value is 0.003. The result is in agreement with Salin finding (2017) in which it emphasizes that MPERS has been designed to fit the local context which is the setting of Malaysia, thus creating certainty for the business to be compatible with the large entities, particularly in terms of measurement, recognition, and judgment, by complying with the standard. 
Table 2. Compliance factors of MPERS implementation by SMEs: Chi-Square Tests

\begin{tabular}{lllll}
\hline Factors & Variable & $\begin{array}{l}\text { Pearson } \\
\text { Chi-Square } \\
\text { value }\end{array}$ & df & $\begin{array}{l}\text { Asymp.sign } \\
\text { (2-sided) }\end{array}$ \\
\hline Legal restriction and requirements & LEGAL & 70.617 & 9 & $0.003^{*}$ \\
External user's perceptions & EXUSER & 48.055 & 9 & 0.161 \\
Management and Accounting Skills & SKILLS & 19.400 & 9 & 0.203 \\
Cost and Benefits of Consideration & COST BENEFIT & 30.932 & 9 & 0.179 \\
Size of entities & SIZE & 26.013 & 9 & 0.051 \\
\hline
\end{tabular}

Notes: * The results are significant at 0.05

Table 3 shows that while other hypotheses had been accepted, only H1 was rejected. From the analysis, the main factor affecting SME compliance with MPERS implementation has been the legal restriction and requirements. MPERS ideally developed to improve the reporting quality of small entities, thus by complying with the standard, if the financial statements is audited by third parties, such as public accounting firms, the truthfulness of the accounting measures and the information will increase. It will thus protect stakeholder interest and boost their confidence in the SMEs' reputation and performance (Jais et al., 2016 and Pais and Bonito, 2018).

The study also reveals that the perception, size of entities, management and accounting skills of the external user, and consideration of costs and benefits, have little impact on MPERS compliance. This indicates by the Chi-square test results that there is no association between the above-mentioned factors with SMEs' compliance with MPERS implementation.

Table 3. Hypotheses on the compliance factors of SMEs with the MPERS implementation

\begin{tabular}{|c|c|c|}
\hline Hypotheses & Null hypotheses (H0) & Accepted or Rejected \\
\hline HI & $\begin{array}{l}\text { There is no relationship between legal restriction and compliance } \\
\text { requirements for SMEs with the MPERS implementation. }\end{array}$ & Rejected \\
\hline$H 2$ & $\begin{array}{l}\text { There is no relationship between the external user's perceptions of } \\
\text { SMEs compliance with the MPERS implementation. }\end{array}$ & Accepted \\
\hline$H 3$ & $\begin{array}{l}\text { There is no relationship between the size of the entities and compliance } \\
\text { by SMEs with the MPERS implementation. }\end{array}$ & Accepted \\
\hline$H 4$ & $\begin{array}{l}\text { There is no relationship between the cost and benefits consideration by } \\
\text { the SMEs with the MPERS implementation. }\end{array}$ & Accepted \\
\hline H5 & $\begin{array}{l}\text { There is no relationship between the management and accounting skills } \\
\text { for SMEs compliance with the MPERS implementation }\end{array}$ & Accepted \\
\hline
\end{tabular}

\section{Discussion and Conclusion}

This study aims objectively to investigate factors affecting MPERS compliance by SMEs in the setting of Malaysia. The survey questionnaire was distributed to accounting practitioners experiencing the implementation of MPERS which has been applied since 1st January 2016. From the analyses carried out, the study found that the legal constraint and requirements have become the main drivers of MPERS compliance. In other words, following the legal restrictions and requirements, it is necessary to ensure that small entities are prepared to move forward to expand their business and be listed on the stock exchange with more stringent rules and rules. Having said that, the SMEs can adopt the more difficult and complicated financial reporting standard for the listed companies by following the strict requirements. It is expected that the findings of this study would match the financial statement to the international standard, so it is expected that SMEs will perceive benefits from MPERS compliance to enhance their international collaboration and cooperation.

However, the current study has some limitations, as the context cannot be generalized as MPERS fits only in the 
environment of Malaysia. But maybe it could be an example of the other Asian region since the business's law system and culture are more or less similar. Additionally, this study is based on the instrument of the survey questionnaire. More need for in-depth analysis and interviews to justify and verify the findings. To overcome these limitations, future research would be conducted. This research aims to assist the standard-setter, the business owners, and regulators of SMEs in identifying the gaps in reporting practices so that stakeholders can perceive the benefits of adopting reports.

\section{Acknowledgements}

This research is benefited from the funding from the Malaysia Ministry of Education for the FRGS Funding with Code: FRGS/1/2018/SS01/USIM/02/3 and Universiti Sains Islam Malaysia (USIM) with Code: USIM/FRGS/FEM/055002/51518 (Benchmarking Malaysian Private Entity Reporting Standard in Malaysia in Achieving High Income Nation).

\section{References}

Abdul Hadi, A. R., Rehan, R., Zainudin, Z., \& Hussain, H. I. (2018). Capital Structure Determinants of Shariah and Non-Shariah Companies at Bursa Malaysia. Opcion, 34(16), 376-386.

Albu, C., Albu, N., \& Alexander, D. (2014). When global accounting standards meet the local context - Insights from an emerging economy. Critical Perspectives on Accounting, 25(6), 489-510.

Aziz, S. A., Bakar, F. A., \& Latif, R. A. (2019). The readiness and Challenges of the Malaysian Private Entities Reporting Standard (MPERS). International Journal of Innovation, Creativity and Change, 5(2), 1621-1634.

Barker, P. C., \& Noonan, C. (1996). Small Company Compliance with Accounting Standards, Dublin University Business School, Dublin.

Dillman, D. A. (2000). Mail and Internet Surveys: The Tailored Design Method. John Wiley \& Sons, New York, NY.

Doupnik, T., \& Slater, S. (1995). External environment, culture and accounting practice: A preliminary test of a general model of international accounting development. International Journal of Accounting, 30, 189-207.

Eierle, B. (2005). Differential reporting in Germany - A historical analysis, Accounting, Business \& Financial History, 15(3), 279-315.

European Commission (EC). (2016). Annual Report on European SMEs2015/2016. Retrieved from https://ec.europa.eu/jrc/sites/jrcsh/files/annual report - eusmes 2015-16.pdf

Felski, E. (2015). Do common features exist among countries that locally adopt IFRS?. International Journal of Accounting and Financial Reporting, 5(2), 144-177.

Holmes, S., Kent, P., \& Downey, G. (1991). The Australian Differential Reporting Debate: A Survey of Practitioners. Accounting and Business Research, 21(82), 125-132.

Husnin, A. I., Nawawi, A., \& Salin, A. S. A. P. (2013). Corporate governance structure and its relationship with audit fee - Evidence from Malaysian public listed companies. Asian Social Science, 9(15), 305-317.

IASB. (2009a). IFRS for SMEs - Project history. Retrieved from http://ifrs.org/IFRS-for-SMEs/history/Pages/History.aspx

IASB. (2017). IFRS for SMEs update. Retrieved from http://www.ifrs.org/-/media/feature/groups/smes/updates/english/2017/ifrs-for-smes-update-march-2017.pdf

Jais, K. M., Nawawi, A., \& Salin, A. S. A. P. (2016). Reduction of audit quality by auditors of small and medium size audit firms in Malaysia: A case of premature sign-off of audit documents. Journal of Accounting, Business \& Management, 23(2), 1-12.

Jamil, N. N., Ramli, N. M., Marzuki, A., \& Ahmad, N. N. (2020). Malaysian Private Entity Reporting Standard (MPERS) For Small Medium Enterprises In Malaysia: Value Adding Or Additional Pain? Perdana: International Journal of Academic Research, 7(1), 16-28.

Jamil, N. N, Ramli, N. M., Marzuki, A., \& Ahmad, N. N. (2020). Malaysia Private Entity Reporting Standard (MPERS) adoption for SMEs: Insights from Accounting Practitioners in Malaysia. Business and Economic Research, 10(2), 104-122.

Kaya, D., \& Koch, M. (2015). Countries adoption of the international financial reporting standard for small and medium-sized entities (IFRS for SMEs) - Early empirical evidence. Accounting and Business Research, 45(1), 
93-120.

Knutson, D., \& Wichmann, H. (1984). GAAP Disclosures: Problem for Small Business?. Journal of Small Business Management, 22(1), 38-46.

Kolsi, M., \& Zehri, F. (2013). The determinants of IAS/IFRS adoption by emergentcountries. In Working paper, Emirates College of Technology, Abu Dhabi.

Koppeschaar, Z. (2012). International Financial Reporting standard for Small and Medium-sized entities. The Southern African Journal of Entrepreneurship and Small Business Management, 5(1), 54-68.

MASB. (2016). Malaysian Private Entities Reporting Standard.

Nijam, H. M. (2016). Impact of IFRS adoption in Sri Lanka: an evaluation of financial reporters' perception. International Journal of Managerial and Financial Accounting, 8(2), 151-171.

Omar, M., Nawawi, A., \& Salin, A. S. A. P. (2016). The causes, impact and prevention of employee fraud: A case study of an automotive company. Journal of Financial Crime, 23(4), 1012-1027.

Pais, C. A. F., \& Bonito, A. L. M. (2018). The macroeconomic determinants of the adoption of IFRS for SMEs. Revista de Contabilidad-Spanish Accounting Review, 21(2), 116-127.

Perera, D., \& Chand, P. (2015). Issues in the adoption of international financial reporting standards (IFRS) for small and medium-sized enterprises (SMES). Advances in accounting, 31(1), 165-178.

Rahim, S. A. A., Nawawi, A., \& Salin, A. S. A. P. (2017). Internal control weaknesses in a cooperative body: Malaysian experience. International Journal Management Practice, 10(2), 131-151.

Salin, A. S. A. P. (2017). Malaysian Private Entities Reporting Standards-Benefits and Challenges to SMEs. International Journal of Academic Research in Business and Social Sciences, 7(11), 1302-1320.

Sia, C. J., Brahmana, R., \& Memarista, G. (2018). Corporate internet reporting and firm performance: Evidence from Malaysia. Contemporary Economics, 12(2), 153-164.

Thi, N., Anh, T., \& Tu, O. (2020). The implication of applying IFRS in Vietnamese enterprises from an expert perspective. Management Science Letters, 10(3), 551-564.

Tong, T. L. (2014). A Comparative Analysis of PERS, MPERS and MFRS Frameworks.

Weaver, L., \& Woods, M. (2015). The challenges faced by reporting entities on their transition to International Financial Reporting Standards: a qualitative study. Accounting in Europe, 12(2), 197-221.

Williams, S., \& Tower, G. (1998). Differential reporting in Singapore and Australia: A small business managers' perspective. The International Journal of Accounting, 33(2), 263-269.

Zehri, F., \& Chouaibi, J. (2013). Adoption determinants of the international accounting standards IAS/IFRS by the developing countries. Journal of Economics, Finance and Administrative Science, 18(35), 56-62.

\section{Copyrights}

Copyright for this article is retained by the author(s), with first publication rights granted to the journal.

This is an open-access article distributed under the terms and conditions of the Creative Commons Attribution license (http://creativecommons.org/licenses/by/4.0/). 